\title{
RETRACTION
}

\section{Evaluation of next-generation sequencing software in mapping and assembly}

\author{
SuYing Bao, Rui Jiang, WingKeung Kwan, BinBin Wang, Xu Ma and You-Qiang Song
}

Journal of Human Genetics (2011) 56, 687; doi:10.1038/jhg.2011.91; published online 11 August 2011

Retraction to: Journal of Human Genetics advance online publication 16 June 2011; doi:10.1038/jhg.2011.62

The publisher is retracting this Review. The same Review was made available online on 28 April 2011 and published in the June issue of Journal of Human Genetics (doi:10.1038/jhg.2011.43).

The Journal of Human Genetics and the publisher would like to apologize to the readers of the journal for the inconvenience caused by this inadvertent error. 